\title{
Cross-sectional and longitudinal associations between receptive arts engagement and loneliness among older adults
}

\author{
Urszula Tymoszuk $^{1,2}\left(\mathbb{D} \cdot\right.$ Rosie Perkins $^{1,2} \cdot$ Daisy Fancourt $^{3} \cdot$ Aaron Williamon $^{1,2}$
}

Received: 29 October 2018 / Accepted: 20 August 2019 / Published online: 11 September 2019

(c) The Author(s) 2019

\begin{abstract}
Purpose Loneliness in older adulthood is a societal and public health challenge warranting identification of sustainable and community-based protective factors. This study investigated whether frequency of receptive arts engagement is associated with lower odds of loneliness in older adults.

Methods We used data of respondents from waves 2 (2004-2005) and 7 (2014-2015) of the English Longitudinal Study of Ageing (ELSA) and examined cross-sectional $(n=6222)$ and longitudinal $(n=3127)$ associations between frequency of receptive arts engagement (including visits to the cinema, museums/galleries/exhibitions, theatre/concerts/opera) and odds of loneliness (cut-off $\geq 6$ on three-item short form of the Revised UCLA Loneliness Scale). We fitted logistic regression models adjusted for a range of sociodemographic, economic, health and social, community and civic engagement factors. Results Cross-sectionally, we found dose-response negative associations between engagement with all receptive arts activities and odds of loneliness. Prospectively, in the fully-adjusted models we found most robust evidence for the negative association between engagement with museums/galleries/exhibitions and odds of loneliness ( $\mathrm{OR}=0.68,95 \%$ CI $0.48-0.95)$ for those who engaged every few months or more often compared with those who never engaged. We found weaker evidence for lower odds of loneliness for more frequent engagement with theatre/concerts/opera.

Conclusions Frequent engagement with certain receptive arts activities and venues, particularly museums, galleries and exhibitions, may be a protective factor against loneliness in older adults. Future research is needed to identify the mechanisms through which this process may occur, leading to better understanding of how arts activities and venues can reduce loneliness among older adults.
\end{abstract}

Keywords Ageing $\cdot$ Arts $\cdot$ Cohort study $\cdot$ Cultural engagement $\cdot$ ELSA $\cdot$ Perceived isolation

This article is part of the focused issue 'Loneliness: contemporary insights on causes, correlates, and consequences'.

\footnotetext{
Aaron Williamon

aaron.williamon@rcm.ac.uk

Urszula Tymoszuk

urszula.tymoszuk@rcm.ac.uk

Rosie Perkins

rosie.perkins@rcm.ac.uk

Daisy Fancourt

d.fancourt@ucl.ac.uk

1 Centre for Performance Science, Royal College of Music, London, UK

2 Faculty of Medicine, Imperial College London, London, UK

3 Department of Behavioural Science and Health, University College London, London, UK
}

\section{Introduction}

Recent research has shown that one in nine people aged 55 years and over living in England between 2016 and 2017 reported feeling lonely always or often, and an additional four in nine reported feeling lonely some of the time [1]. Concurrently, the total population of adults aged 55 years and above living in the UK is predicted to increase, from over 19 million in 2016 to over 26 million (i.e. more than one in three people) by 2040 [2]. As loneliness and inadequate social relationships have been previously linked with, for instance, increased risk of depressive symptoms [3], coronary heart disease and stroke [4], and mortality [5], this demographic change combined with vulnerability to loneliness among older adults poses a significant societal and public health challenge. 
The risk of loneliness increases with age due to factors such as bereavement, decline in physical health, cognitive function and mobility as well as changes in living and socioeconomic circumstances, including living alone or in a nursing home [6-9]. Previous research also highlights the significance of declining and infrequent social participation as one of the risk factors for loneliness in old age $[9,10]$. Contrary to this, sustained social and community participation, as well as frequent social contact with close others such as family members and social support, can protect against loneliness $[8,10]$. There is, therefore, a need to identify sustainable, community-based solutions to foster social interactions and prevent loneliness in older adults.

In recent years, engagement with arts-based activities and venues has been increasingly used as a key ingredient of public health interventions [11,12], leading to reports of multiple health and well-being benefits associated with cultural and arts engagement in older adulthood [13, 14]. Arts engagement within general population-based health research usually refers to broadly defined expressed or experienced human artistic creativity $[14,15]$ and is commonly conceptualised as participatory engagement with the arts (active creation of visual arts, drama, music or other art forms), and receptive arts engagement (attendance at arts-based events and venues such as museums, galleries, concert halls, and theatres). The majority of the evidence to date describes health and well-being benefits associated with participatory arts engagement for older adults [13, 14]. Nonetheless, frequent receptive arts engagement has been previously linked, among others, with lower odds of incident depressive symptoms and higher levels of happiness, life satisfaction, self-realisation and perceived independence in the English Longitudinal Study of Ageing (ELSA) dataset $[16,17]$ as well as lower odds of poor self-rated health and mortality in Swedish adult population-representative, prospective studies $[18,19]$.

The role of participatory and receptive arts engagement in preventing or alleviating loneliness among older adults, as well as facilitating bonding in new and existing relationships, has been also increasingly recognised [20, 21]. The most substantial body of evidence to date documents the role of music in preventing feelings of loneliness as well as sustaining social activity and independence in old age [22-26]. For instance, participation in community-based choir groups has been linked to a decrease in loneliness levels over a 2 year period [27], whilst making music such as singing in a choir or learning to make music has been also found to facilitate forming new social relationships and cultivating existing ones by providing opportunities for social affirmation, social support, and new forms of interaction [23, $25,26,28]$. Studies involving adult populations further suggest that engagement with group-based musical and other creative activities increases the pace of social bonding and perceptions of closeness among participants, with some evidence suggesting a stronger effect for singing compared with other activities [29, 30], albeit inconsistently [31]. Others also demonstrated that visual art can be used to stimulate participation in a social network [32], and similar beneficial relational changes, such as increasing the number and closeness of social relationships, were observed for older adults participating in creative arts programmes [33] and painting workshops [34]. Most recently, museum-based programs for isolated older adults were also found to foster social inclusion by enabling social interactions and cultivation of meaningful relationships [21].

The evidence to date indicates that arts engagement in older age may serve as a multimodal intervention helping to prevent loneliness and enhance social interactions alongside other aspects of well-being and health. However, the majority of this evidence is based on small-scale and shortterm intervention studies assessing the impact of participatory arts-based programmes run for a limited period of time and prone to significant self-selection bias. Receptive arts engagement should not be overlooked. In the UK there are over 2500 museums [35], 1300 theatres [36], and 4000 libraries [37] as well as 400 historic places [38], and 10,000 village halls [39] in England alone. These venues provide social spaces and opportunities to engage with the arts and leisure activities, and could be utilised as 'assets' to help reduce loneliness within communities. Yet, to the best of our knowledge, there are no previous large-scale, general population-based studies examining receptive arts engagement and its association with loneliness in older adulthood. To address this, we have used data from a large, nationally representative dataset of older adults aged over 50 years, the English Longitudinal Study of Ageing (ELSA), and investigated associations between frequency of visits to (i) the cinema, (ii) art galleries, exhibitions or museums, and (iii) the theatre, concerts, or the opera and odds of loneliness at baseline and 10 years later.

\section{Methods}

\section{Data and study sample}

We used data from the English Longitudinal Study of Ageing (ELSA), a large, ongoing longitudinal cohort study representative of the non-institutionalised English population of people aged 50 years and older on enrolment in 2002-2003 and designed as a stratified random sample of private households drawn originally from 1998, 1999, and 2001 Health Survey for England (HSE) [40]. For ELSA wave 1, participants born before 1 March 1952 and living in a private household in England participating in HSE, in which at least one person consented to follow-up, were considered eligible 
to participate [40]. Partners living in the same household as 'core' study member were also eligible to participate in the study. ELSA wave 1 household and individual response rates were $70 \%$ and $67 \%$, respectively [40]. The participants were followed-up at 2-yearly intervals and the original sample was refreshed with additional HSE respondents to maintain the general population representativeness [40]. We specifically worked with data from 'core' ELSA members who took part in wave 2 (2004-2005) and wave 7 (2014-2015). Our analytical samples consisted of participants with complete arts engagement, covariate and loneliness data at wave 2 for cross-sectional analyses $(n=6222)$, and additionally complete loneliness data at wave 7 for longitudinal analyses $(n=3127)$.

\section{Loneliness}

Loneliness was measured using the three-item short-form of the Revised UCLA Loneliness Scale which has been previously demonstrated to have good convergent and discriminant validity [41]. The three items assess how often the participants feel "left out", "isolated from others", and "lack companionship". The answers are rated on a threepoint scale-1 (hardy ever or never), 2 (some of the time), 3 (often) - and summed to produce a score ranging from 3 to 9 , with higher scores indicating greater loneliness. Due to significant positive skew, the score was dichotomised to create a binary variable, grouping participants scoring 3-5 as "not lonely" and those scoring "6-9" as "lonely" in agreement with previous practice $[42,43]$.

\section{Arts engagement}

Arts engagement was self-reported by the participants at wave 2 and consisted of three items asking about the frequency of visits to: (a) the cinema, (b) art galleries, exhibitions or museums, (c) the theatre, concerts, or the opera. Each arts engagement item was assessed on a five-point scale: 0 (never), 1 (less than once a year), 2 (once or twice a year), 3 (every few months), 4 (once a month or more). The two most frequent categories were combined for analyses due to a small sample size, creating an "every few months or more" category.

\section{Covariates}

Variables considered likely to confound the associations between arts engagement and loneliness were measured at baseline (wave 2). Demographic covariates included age, gender, and ethnicity (coded as White and non-White as ELSA is $>98 \%$ white British). Socioeconomic status was assessed with highest educational attainment (categorised as: University degree or equivalent, including NVQ4-NVQ5;
A level/higher education or equivalent including NVQ3; the General Certificate of Education incl. Ordinary level qualification (GCE/O level) or equivalent including NVQ2; other or no educational qualification), employment status (fulltime, part-time, not in employment) and net non-pension wealth quintiles which measure the accumulation of assets over the lifespan and have been previously reported as the most salient socioeconomic position indicator in the ELSA cohort [44]. Health covariates included long-standing illness status (no long-standing illness, long-standing and nonlimiting illness, long-standing and limiting illness), eyesight and hearing problems, as well as experiences of moderate or severe pain that could hinder one's overall arts engagement. Additionally, participants registered as blind $(n=33)$ were excluded from the analyses due to possible different profiles of engagement in arts activities. Social factors included: coupled relationship status (in a couple vs. without a partner); a social contact variable derived as a composite score of frequency of contact (including contact over the phone, email, and face to face) with friends, children and wider relatives (coded as +1 for each mode of contact and social tie, if contact occurred on a monthly basis or more frequently, with the score ranging 0-9); and a binary variable specifying engagement in any community activities (including being a member of a political party or environmental group, a tenants or neighbourhood watch group, a church or religious association, a charitable association, an education, arts or music class, a social club, a sports, gym or exercise class, or any other society).

\section{Statistical analysis}

We investigated the association between three receptive arts engagement activities visits to (a) the cinema, (b) museums/ galleries/exhibitions, and (c) theatre/concerts/opera-at baseline (wave 2) and odds of loneliness cross-sectionally (at wave 2) and longitudinally, a decade later (at wave 7). We used univariable (Model 1) and multivariable logistical regression models, adjusted for demographic and socioeconomic covariates (gender, age, ethnicity, highest educational attainment, employment status, and net non-pension wealth, Model 2), health variables (long-standing illness status, eyesight and hearing problems and pain, Model 3) and social factors (coupled relationships status, social contact score and engagement with community activities, Model 4). Model 5 additionally adjusted for wave 2 loneliness in the longitudinal analysis to establish if the associations between the odds of loneliness and arts engagement remain after controlling for baseline loneliness.

All analyses were weighted using baseline cross-sectional weights to minimise bias from differential non-response amongst key subgroups. Participants with missing information on arts engagement, covariates and loneliness at wave 2 
were excluded from cross-sectional analyses, yielding a final cross-sectional analytical sample of 6222 . Out of these, 3095 participants who missed ELSA wave 7 and did not provide wave 7 loneliness data were excluded from the longitudinal analytical sample, yielding a final longitudinal analytical sample of $n=3127$. As a sensitivity analysis, missing covariate data were imputed using multiple imputation by chained equations; however, the results of the analyses did not vary materially between complete case and imputed datasets, hence the findings presented here are based on the complete case dataset.

\section{Results}

The analytical samples used for cross-sectional and longitudinal analyses are described in Table 1. The sample included in the longitudinal sample was predominantly White British, the mean age was 62.5 years of age and $44.9 \%$ of participants were men. Approximately $50 \%$ of participants reported no formal education or GCE/O level as the highest educational qualification and $54.8 \%$ were not in employment. Just over $50 \%$ of participants reported having long-standing illness, $8.0 \%$ had eyesight problems, $16.5 \%$ had hearing problems and $5.4 \%$ reported pain. Approximately $75 \%$ were in a coupled relationship and $79.1 \%$ were engaged in community and civic activities. On average participants scored 4.8 out of 9 on the social contact scale. Most frequent arts engagement, taking place every few months or more often, was reported by $25.9 \%, 19.8 \%$ and $27.3 \%$ of participants for visits to the cinema, galleries/exhibitions/museums, and theatre/concerts/opera, respectively. No arts engagement was reported by $30.0 \%, 29.0 \%$ and $24.5 \%$ of participants for visits to the cinema, galleries/exhibitions/museums, and theatre/concerts/opera, respectively. Of 6222 participants at wave $2,18.9 \%(n=1178)$ were lonely, of those $47.8 \%$ remained lonely and $52.2 \%$ no longer reported loneliness at wave 7 . Just over $16 \%(n=510)$ of participants reported loneliness at wave 7 .

\section{Cross-sectional analysis}

The results from cross-sectional logistic regression models are presented in Table 2. We found dose response, negative associations between odds of loneliness and engagement with cinema, galleries/exhibitions/museums and theatre/concerts/opera. In the final, fully-adjusted models, we found that engaging with cinema every few months or more often, compared with never, was associated with $26 \%$ lower odds of loneliness $(\mathrm{OR}=0.74,95 \%$ confidence interval $(\mathrm{CI})$ $0.59-0.93, p=0.009)$. Participants reporting visits to galleries/exhibitions/museums every few months or more often and once or twice a year had, respectively, $26 \%(\mathrm{OR}=0.74$,
95\% CI $0.57-0.94, p=0.016)$ and $22 \%(\mathrm{OR}=0.78,95 \%$ CI $0.62-0.97, p=0.024)$ lower odds of loneliness compared with those who reported no engagement. Participants reporting visits theatre/concerts/opera every few months or more often and once or twice a year had, respectively, $33 \%(\mathrm{OR}=0.67,95 \%$ CI $0.53-0.84, p=0.001)$ and $23 \%$ (OR $=0.77,95 \%$ CI $0.62-0.95, p=0.013$ ) lower odds of loneliness compared with those who reported no engagement.

\section{Longitudinal analysis}

The results from longitudinal logistic regression models are presented in Table 3. We found no association between frequency of engagement with cinema and odds of loneliness after adjusting for covariates. We found a dose response, negative association between engagement with galleries/exhibitions/museums and odds of loneliness, which remained after all adjustments. In the final, fully-adjusted model, engaging with galleries/exhibitions/museums every few months or more often, compared with never, was associated with $32 \%$ lower odds of reporting loneliness at wave $7(\mathrm{OR}=0.68,95 \%$ CI $0.48-0.95, p=0.025)$ and engaging once or twice a year was associated with $26 \%$ lower odds of reporting loneliness at wave $7(\mathrm{OR}=0.74,95 \%$ CI $0.54-1.01, p=0.055)$. We also found evidence, albeit less consistent, to suggest that more frequent engagement with the theatre/concerts/opera was associated with lower odds of loneliness over time. In the fully-adjusted model, engaging with the theatre/concerts/opera once or twice a year, compared with never, was associated with $31 \%$ lower odds of reporting loneliness at wave $7(\mathrm{OR}=0.69,95 \% \mathrm{CI}$ $0.50-0.95, p=0.021)$. Further, compared with no engagement with the theatre/concerts/opera, engagement every few months or more often ceased to be significantly associated with odds of loneliness once social factors were accounted for, whilst engagement on a less than once a year basis remained associated with lower odds of loneliness (Model $4, \mathrm{OR}=0.75,98 \%$ CI $0.56-0.99, p=0.046$ ).

Finally, it is worth to note that the longitudinal analytical sample was skewed towards participants who were female, younger, employed, more educated, in good health, coupled relationships, reporting greater social, community and arts engagement as well as less likely to be lonely at wave 2 (Table 1).

\section{Discussion}

This study using a large sample of the ELSA dataset found that frequent receptive arts engagement was associated with lower odds of loneliness contemporaneously, and a decade later. In cross-sectional fully-adjusted analyses at 
Table 1 Descriptive characteristics of participants included in the complete cases analyses of cross-sectional sample $(n=6222)$ and longitudinal sample $(n=3127)$, and those excluded from longitudinal analysis $(n=3095)$

\begin{tabular}{|c|c|c|c|c|}
\hline Covariates at wave 2 & $\begin{array}{l}\text { Cross-sectional } \\
\text { sample }(n=6222)\end{array}$ & $\begin{array}{l}\text { Longitudi- } \\
\text { nal sample } \\
(n=3127)\end{array}$ & $\begin{array}{l}\text { Excluded sam- } \\
\text { ple }(n=3095)\end{array}$ & $p$ \\
\hline Gender: male, $n(\%)$ & $2896(46.5 \%)$ & $1405(44.9 \%)$ & $1491(48.2 \%)$ & 0.010 \\
\hline Age, mean (SD) & $65.60(9.46)$ & $62.50(7.15)$ & $68.72(10.43)$ & $<0.001$ \\
\hline Ethnicity: Non-white, $n(\%)$ & $87(1.4 \%)$ & $36(1.2 \%)$ & $51(1.7 \%)$ & 0.10 \\
\hline \multicolumn{5}{|l|}{ Education, $n(\%)$} \\
\hline Degree & $882(14.2 \%)$ & $552(17.6 \%)$ & $330(10.7 \%)$ & \multirow[t]{4}{*}{$<0.001$} \\
\hline A level/higher education & $1858(29.9 \%)$ & $1018(32.6 \%)$ & $840(27.1 \%)$ & \\
\hline GCE and $\mathrm{O}$ level & $1161(18.7 \%)$ & $685(21.9 \%)$ & $476(15.4 \%)$ & \\
\hline No qualification & $2321(37.3 \%)$ & $872(27.9 \%)$ & $1449(46.8 \%)$ & \\
\hline \multicolumn{5}{|l|}{ Employment status, $n(\%)$} \\
\hline Not in employment & $4009(64.4 \%)$ & $1712(54.8 \%)$ & $2297(74.2 \%)$ & \multirow[t]{3}{*}{$<0.001$} \\
\hline Full time $\geq 35 \mathrm{~h} /$ week & $1275(20.5 \%)$ & $804(25.7 \%)$ & $471(15.2 \%)$ & \\
\hline Part time & $938(15.1 \%)$ & $611(19.5 \%)$ & $327(10.6 \%)$ & \\
\hline \multicolumn{5}{|l|}{ Long-standing illness, $n(\%)$} \\
\hline No long-standing illness & $2755(44.3 \%)$ & $1532(49.0 \%)$ & $1223(39.5 \%)$ & \multirow[t]{3}{*}{$<0.001$} \\
\hline Long-standing, not limiting illness & $1403(22.5 \%)$ & $770(24.6 \%)$ & $633(20.5 \%)$ & \\
\hline Long-standing and limiting illness & $2064(33.2 \%)$ & $825(26.4 \%)$ & $1239(40.0 \%)$ & \\
\hline Eyesight problems: Yes, $n(\%)$ & $720(11.6 \%)$ & $249(8.0 \%)$ & $471(15.2 \%)$ & $<0.001$ \\
\hline Hearing problems: Yes, $n(\%)$ & $1260(20.3 \%)$ & $515(16.5 \%)$ & $745(24.1 \%)$ & $<0.001$ \\
\hline Pain: Yes, $n(\%)$ & $430(6.9 \%)$ & $169(5.4 \%)$ & $261(8.4 \%)$ & $<0.001$ \\
\hline Coupled relationship status: Yes, $n(\%)$ & $4418(71.0 \%)$ & $2357(75.4 \%)$ & $2061(66.6 \%)$ & $<0.001$ \\
\hline Social contact score $(0-9)$, mean (SD) & $4.63(1.85)$ & $5.82(1.81)$ & $4.44(1.87)$ & $<0.001$ \\
\hline Community engagement: Yes, $n(\%)$ & $4622(74.3 \%)$ & $2473(79.1 \%)$ & $2149(69.4 \%)$ & $<0.001$ \\
\hline \multicolumn{5}{|l|}{ Frequency of arts engagement } \\
\hline \multicolumn{5}{|l|}{ Cinema, $n(\%)$} \\
\hline Never & $2520(40.5 \%)$ & $937(30.0 \%)$ & $1583(51.2 \%)$ & \multirow[t]{4}{*}{$<0.001$} \\
\hline Less than once a year & $1418(22.8 \%)$ & $776(24.8 \%)$ & $642(20.7 \%)$ & \\
\hline Once or twice a year & $1018(16.4 \%)$ & $603(19.3 \%)$ & $415(13.4 \%)$ & \\
\hline Every few months or more & $1266(20.3 \%)$ & $811(25.9 \%)$ & $455(14.7 \%)$ & \\
\hline \multicolumn{5}{|l|}{ Galleries/exhibitions/museums, $n(\%)$} \\
\hline Never & $2451(39.4 \%)$ & $908(29.0 \%)$ & $1534(49.9 \%)$ & \multirow[t]{4}{*}{$<0.001$} \\
\hline Less than once a year & $1562(25.1 \%)$ & $883(28.3 \%)$ & $679(21.9 \%)$ & \\
\hline Once or twice a year & $1220(19.6 \%)$ & $716(22.9 \%)$ & $504(16.3 \%)$ & \\
\hline Every few months or more & $989(15.9 \%)$ & $620(19.8 \%)$ & $369(11.9 \%)$ & \\
\hline \multicolumn{5}{|l|}{ Theatre/concerts/opera, $n(\%)$} \\
\hline Never & $2133(34.3 \%)$ & $766(24.5 \%)$ & $1367(44.2 \%)$ & \multirow[t]{5}{*}{$<0.001$} \\
\hline Less than once a year & $1305(21.0 \%)$ & $699(22.4 \%)$ & $606(19.6 \%)$ & \\
\hline Once or twice a year & $1374(22.1 \%)$ & $807(25.8 \%)$ & $567(18.3 \%)$ & \\
\hline Every few months or more & $1410(22.6 \%)$ & $855(27.3 \%)$ & $555(17.9 \%)$ & \\
\hline Loneliness (score $\geq 6$ ) at wave 2 & $1178(18.9 \%)$ & - & - & \\
\hline Loneliness (score $\geq 6$ ) at wave 7 & - & $510(16.3 \%)$ & $668(21.6 \%)$ & $<0.001$ \\
\hline
\end{tabular}

$P$ values correspond to statistical differences between samples included and excluded from the longitudinal analysis. Data comes from ELSA study waves 2 (2004-2005) and 7 (2014-2005)
ELSA wave 2, we found that frequent engagement with all three activities (cinema, galleries/exhibitions/museums, theatre/concerts/opera) was associated with lower odds of loneliness. Longitudinally, we found that frequent visits to galleries, exhibitions and museums in particular, as well as to some degree frequent visits to the theatre, concerts and opera may be modestly protective against loneliness over time. We found that these associations were independent of baseline loneliness score and a number of sociodemographic, socioeconomic and health factors, plus other forms of social engagement such as frequency of contact 
Table 2 Results from logistic regression models examining the association between baseline (2004-2005) arts engagement and odds of loneliness (UCLA-3 item $\geq 6$ ) at ELSA wave 2 (2004-2005), $n=6222$

\begin{tabular}{|c|c|c|c|c|c|c|c|c|c|c|c|c|}
\hline & \multicolumn{3}{|c|}{ Model 1} & \multicolumn{3}{|c|}{ Model 2} & \multicolumn{3}{|c|}{ Model 3} & \multicolumn{3}{|c|}{ Model 4} \\
\hline & OR & $95 \% \mathrm{CI}$ & $p$ & OR & $95 \% \mathrm{CI}$ & $p$ & OR & $95 \% \mathrm{CI}$ & $p$ & OR & $95 \% \mathrm{CI}$ & $p$ \\
\hline \multicolumn{13}{|c|}{ Frequency of visits to the cinema (reference: never) } \\
\hline$\leq$ Once a year & 0.64 & $0.54-0.76$ & $<0.001$ & 0.84 & $0.71-1.01$ & 0.068 & 0.91 & $0.76-1.10$ & 0.32 & 0.98 & $0.81-1.18$ & 0.81 \\
\hline Once or twice a year & 0.56 & $0.46-0.68$ & $<0.001$ & 0.78 & $0.63-0.97$ & 0.023 & 0.88 & $0.71-1.09$ & 0.25 & 0.91 & $0.73-1.14$ & 0.44 \\
\hline$\geq$ Every few months & 0.44 & $0.37-0.54$ & $<0.001$ & 0.64 & $0.52-0.80$ & $<0.001$ & 0.73 & $0.59-0.91$ & 0.005 & 0.74 & $0.59-0.93$ & 0.009 \\
\hline \multicolumn{13}{|c|}{ Frequency of visits to galleries/exhibitions/museums (reference: never) } \\
\hline$\leq$ Once a year & 0.53 & $0.45-0.62$ & $<0.001$ & 0.69 & $0.58-0.83$ & $<0.001$ & 0.78 & $0.65-0.94$ & 0.007 & 0.83 & $0.68-1.01$ & 0.63 \\
\hline Once or twice a year & 0.46 & $0.38-0.56$ & $<0.001$ & 0.65 & $0.53-0.79$ & $<0.001$ & 0.74 & $0.60-0.91$ & 0.005 & 0.78 & $0.62-0.97$ & 0.024 \\
\hline$\geq$ Every few months & 0.44 & $0.36-0.55$ & $<0.001$ & 0.65 & $0.51-0.82$ & $<0.001$ & 0.75 & $0.59-0.95$ & 0.016 & 0.74 & $0.57-0.94$ & 0.016 \\
\hline \multicolumn{13}{|c|}{ Model 1: Frequency of visits to the theatre/concerts/opera (reference: never) } \\
\hline$\leq$ Once a year & 0.60 & $0.50-0.72$ & $<0.001$ & 0.76 & $0.63-0.92$ & 0.004 & 0.84 & $0.69-1.02$ & 0.08 & 0.88 & $0.72-1.07$ & 0.21 \\
\hline Once or twice a year & 0.48 & $0.40-0.57$ & $<0.001$ & 0.63 & $0.52-0.77$ & $<0.001$ & 0.72 & $0.59-0.88$ & 0.001 & 0.77 & $0.62-0.95$ & 0.013 \\
\hline$\geq$ Every few months & 0.39 & $0.33-0.48$ & $<0.001$ & 0.55 & $0.45-0.69$ & $<0.001$ & 0.65 & $0.52-0.81$ & $<0.001$ & 0.67 & $0.53-0.84$ & 0.001 \\
\hline
\end{tabular}

Model 1 univariate, Model 2 demographic factors: Model $1+$ gender, age, ethnicity, highest educational attainment, employment status, and net non-pension wealth, Model 3 health factors: Model 2+health variables: eyesight and hearing problems, experiences of pain and long-standing illness status, Model 4 social factors: Model 3 + social contact, romantic relationship status, and engagement with community activities

with friends, family, children and participation in different community activities.

Our longitudinal findings are in line with previous research focusing on museum and gallery attendance. Todd et al. reported on a series of museum programmes designed to engage socially isolated older adults in participatory activities including object handing, participatory arts and singing. These programmes were found to aid perceived social inclusion by providing a context for social interactions and a safe and stimulating space that enabled positive change for the individual such as enhanced self-esteem and positive interpersonal experiences including opportunities for social interactions and cultivating relationships [21]. Art gallery-based interventions for people with dementia and their careers have been also found to foster feelings of social inclusion as well as emotional closeness in pairs [45]. Similarly, the monthly Meet Me at MoMA programme, run at the Museum of Modern Art in New York for people in the early and middle stage of Alzheimer's disease and their carers was observed to support and facilitate shared experiences as well as being an inherently social experience [46]. Indeed, Camic and Chatterjee argue that museums and art galleries play an important social role in the health and wellbeing of communities [11]. Other intervention studies also demonstrate that participatory engagement with visual arts within community setting helped older adults to overcome prolonged social isolation and facilitated socialising with others [32, 34].

We found lesser evidence of a longitudinal protective association for older adults' engagement with the theatre, concerts and opera and no longitudinal association between engagement with the cinema and loneliness. While all arts activities measured in this study could be described as receptive forms of arts engagement, i.e. attending rather than participating at arts events and venues, the more passive and least interactive activities-including cinemamay be the least conducive to counteracting loneliness in older adults. Indeed, it has been suggested that participatory arts, involving active involvement in arts-based activities, may be most effective at tackling loneliness and assisting isolated older adults in regaining their confidence to reconnect with others [20]. However, no empirical comparisons of participatory and receptive art engagement and loneliness have been produced to date. Art-based participatory interventions are usually run for a limited time and require a dedicated and skilled programme leader, which poses numerous sustainability challenges. Here, we demonstrate that frequent self-directed arts attendance may also help to protect older adults from loneliness. Nonetheless, specific programmes and skilled staff members are necessary to facilitate greater access and social inclusion required to foster positive social outcomes, particularly for isolated and vulnerable older adults such as people with dementia and their carers [21, 45]. It is also acknowledged that the measure of arts engagement used in ELSA was not detailed enough to preclude the possibility of more participatory forms of engagement during participants' arts activities. For instance, the study participants may have visited cultural venues such as museums and galleries to take part in participatory workshops or activities such as educational classes. Further research is needed to investigate the differences between art forms and cultural venues 


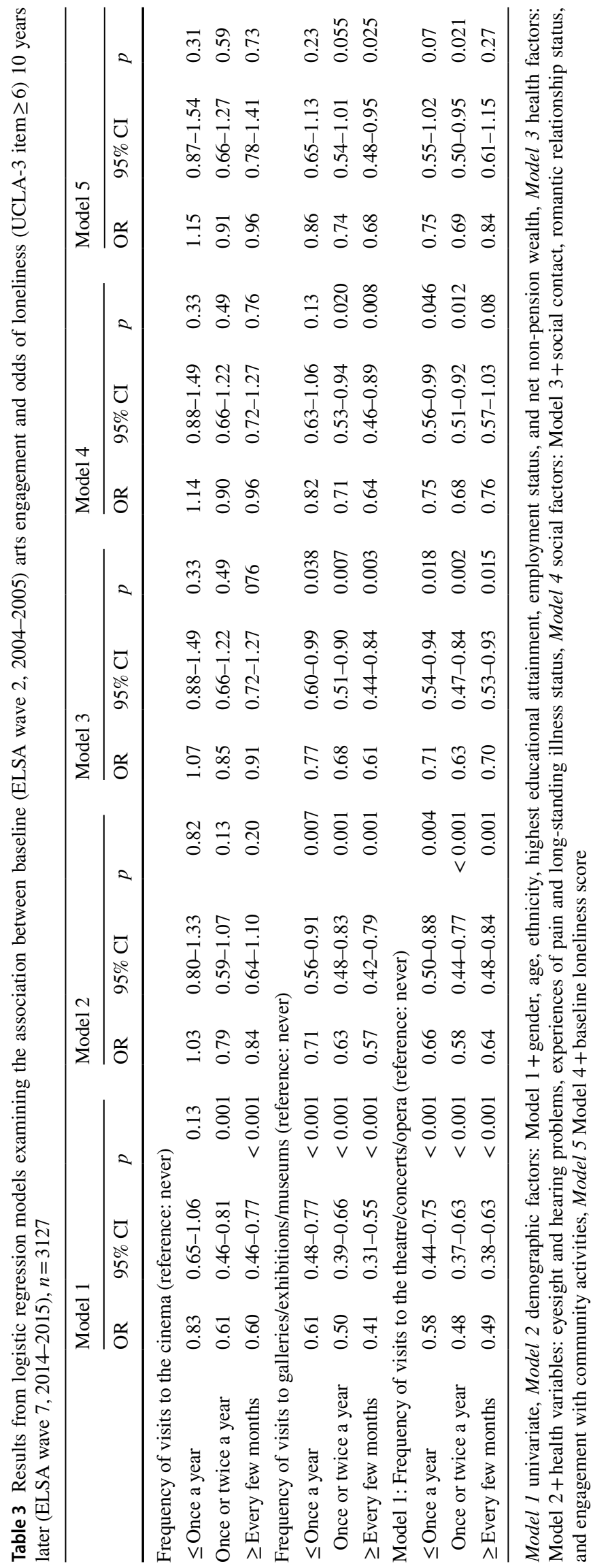


in opportunities for social inclusion and shared experiences facilitating positive social contact of older adults.

Multiple beneficial social outcomes associated with arts engagement have been identified that can help to elucidate its role in counteracting loneliness [47]. For instance, engagement with music has been reported by older adults as a direct coping strategy for avoiding and alleviating feelings of loneliness [22, 48]. In fact, regulation of feelings of loneliness is one of the motivations for listening to music frequently reported in the wider literature $[49,50]$. Arts engagement is often a social activity in itself as people tend to attend arts-based events and venues accompanied and for the shared positive social experiences [21, 51]. The atmosphere of social inclusion present in the art spaces can be particularly conducive to older adults who may need additional support to re-connect with others, particularly in overcoming the challenge of prolonged isolation and/or low selfesteem and confidence [21,33]. Arts-based activities have been further found to facilitate the creation of new social relationships [21, 26, 32, 33] and increase the pace of bonding and closeness in relationships [30, 33, 52]. Relationships created or strengthened as part of engaging with the arts, such as making music in local community groups can increase access to different forms of support, such as peer or informational support, and act as a source of social affirmation $[23,26]$. Arts-based activities have been also shown to increase closeness of existing family and peer relationships by extending the usual types of shared activities and interactions $[25,34,51]$ as well as to boost feelings of belonging on a larger scale by increasing connectedness in the wider community [26, 53]. Consequently, arts-based engagement has the potential to facilitate several of the intervention strategies identified previously [54] as relevant to reducing loneliness: improving social skills, enhancing social support, increasing opportunities for social contact, and to some, yet limited, extent addressing maladaptive social cognition [21]. Further research exploring how receptive arts activities specifically may protect older adults against loneliness, and how they compare to participatory arts activities as well as other leisure and hobby activities such as sports, is still warranted. As arts engagement is often a shared experience, future research is needed to understand the interplay between the social and creative processes occurring in encounters with the arts. More research is also needed to understand barriers and facilitators of arts engagement in lonely and isolated adults.

\section{Strengths and limitations}

The study is the first to address the association between receptive arts engagement and loneliness in old age using a large, general population-based cohort study with rich information on health and social covariates, and a longitudinal design. Nonetheless, it also includes several limitations. Our estimates are likely biased by non-random attrition commonly found in observational, longitudinal research. We found that participants included in the final analytical sample were younger, more educated, healthier and more socially engaged. These patterns of attrition might have increased the study's vulnerability to residual confounding by socioeconomic and health status differences in access and engagement with arts activities. We further found that participants excluded from the analytical sample were more likely to report no arts engagement and loneliness at baseline, which could further bias the findings, yet likely leading to an underestimation of the association.

This study also suffers from bias resulting from measurement issues related to arts engagement, which requires longer and more comprehensive scales in order to shed light on the plethora of ways in which older adults can engage in arts activities. Compared with lists of activities measured in other surveys, such as Understanding Society, the number of arts-based activities included in ELSA is limited and restricted to engagement in receptive and usually ticketed arts activities occurring in government-supported or commercial cultural venues, thus likely leading to underestimated and biased representation of arts engagement in the population [55]. The conceptualisation of arts engagement in ELSA is not, however, atypical in its the omission of more popular forms of cultural participation, including participatory arts and thus bias towards "highbrow interpretation" of what constitutes arts engagement [55-57].

\section{General conclusions}

Our study has shown that frequent arts engagement in older adults is associated with reduced odds of loneliness contemporaneously, and 10 years later. We find that frequent visits to galleries, exhibitions and museums in particular appear to be protective against loneliness in older adults over time, independently of baseline loneliness level and various demographic, socioeconomic, health and social factors. If replicated in future studies, these findings would suggest that those who manage places and spaces for arts engagement should, at the least, be aware of the potential for their venues to facilitate shared experiences and positive social interactions and, even better, direct their resources and programming toward facilitating such opportunities. Future research is needed to understand the mechanisms through which different arts activities, in particular receptive arts engagement, can contribute to preventing and alleviating feelings of loneliness and facilitating social connectedness among older adults. 
Acknowledgements The English Longitudinal Study of Ageing (ELSA) was developed by a team of researchers based at the University College London, NatCen Social Research, the Institute for Fiscal Studies, and the University of Manchester. The data were collected by NatCen Social Research. The funding for ELSA is provided by National Institute of Aging Grant R01AG017644 and a consortium of UK government departments coordinated by the Economic and Social Research Council.

Funding The research reported in this article was supported by HEartS, a project funded by the UK's Arts and Humanities Research Council to investigate the health, economic and social impact of the arts (Grant ref. AH/P005888/1). UT, RP, AW are funded through HEartS (AH/P005888/1) and DF is supported by the Wellcome Trust [205407/Z/16/Z].

\section{Compliance with ethical standards}

Conflict of interest The authors declare that they have no competing interest.

Ethical approval ELSA study has been approved by the appropriate ethics committee and has therefore been performed in accordance with the ethical standards laid down in the 1964 Declaration of Helsinki and its later amendments.

Open Access This article is distributed under the terms of the Creative Commons Attribution 4.0 International License (http://creativeco mmons.org/licenses/by/4.0/), which permits unrestricted use, distribution, and reproduction in any medium, provided you give appropriate credit to the original author(s) and the source, provide a link to the Creative Commons license, and indicate if changes were made.

\section{References}

1. Office for National Statistics (2018) Loneliness-what characteristics and circumstances are associated with feeling lonely? London: Office for National Statistics. https://www.ons.gov.uk/ peoplepopulationandcommunity/wellbeing/articles/loneliness whatcharacteristicsandcircumstancesareassociatedwithfeelingl onely/2018-04-10. Accessed 3 Jul 2019

2. Office for National Statistics (2017) National Population Projections: 2016-based statistical bulletin. London: Office for National Statistics. Retrieved from https://www.ons.gov.uk/releases/natio nalpopulationprojections2016basedstatisticalbulletin. Accessed 3 Jul 2019

3. Cacioppo JT, Hawkley LC, Thisted RA (2010) Perceived social isolation makes me sad: 5-year cross-lagged analyses of loneliness and depressive symptomatology in the Chicago Health, Aging, and Social Relations Study. Psychol Aging 25:453-463. https:// doi.org/10.1037/a0017216

4. Valtorta NK, Kanaan M, Gilbody S et al (2016) Loneliness and social isolation as risk factors for coronary heart disease and stroke: systematic review and meta-analysis of longitudinal observational studies. Heart 102:1009-1016. https://doi.org/10.1136/ heartjnl-2015-308790

5. Holt-Lunstad J, Smith TB, Layton JB (2010) Social relationships and mortality risk: a meta-analytic review. PLoS Med 7:e1000316

6. Pinquart M, Sorensen S (2001) Influences on loneliness in older adults: a meta-analysis. Basic Appl Soc Psych 23:245-266. https ://doi.org/10.1207/S15324834BASP2304_2
7. Hansen T, Slagsvold B (2016) Late-life loneliness in 11 European countries: results from the generations and gender survey. Soc Indic Res 129:445-464. https://doi.org/10.1007/s1120 5-015-1111-6

8. Fokkema T, De Jong Gierveld J, Dykstra PA (2012) Cross-national differences in older adult loneliness. J Psychol 146:201-228. https ://doi.org/10.1080/00223980.2011.631612

9. Aartsen M, Jylhä M (2011) Onset of loneliness in older adults: results of a 28 year prospective study. Eur J Ageing 8:31-38. https://doi.org/10.1007/s10433-011-0175-7

10. Niedzwiedz CL, Richardson EA, Tunstall $\mathrm{H}$ et al (2016) The relationship between wealth and loneliness among older people across Europe: is social participation protective? Prev Med (Baltim) 91:24-31. https://doi.org/10.1016/j.ypmed.2016.07.016

11. Camic PM, Chatterjee HJ (2013) Museums and art galleries as partners for public health interventions. Perspect Public Health 133:66-71. https://doi.org/10.1177/1757913912468523

12. Stuckey HL, Nobel J (2010) The connection between art, healing, and public health: a review of current literature. Am J Public Health 100:254-263. https://doi.org/10.2105/ AJPH.2008.156497

13. Noice T, Noice H, Kramer AF (2014) Participatory arts for older adults: a review of benefits and challenges. Gerontologist 54:741753. https://doi.org/10.1093/geront/gnt138

14. All-Party Parliamentary Group on Arts Health and Wellbeing (2017) Creative health: the arts for health and wellbeing, 2nd edition. https://www.artshealthandwellbeing.org.uk/appg-inqui ry/. Accessed 3 Jul 2019

15. Davies CR, Rosenberg M, Knuiman M et al (2012) Defining arts engagement for population-based health research: art forms, activities and level of engagement. Arts Health 4:203-216. https ://doi.org/10.1080/17533015.2012.656201

16. Fancourt D, Tymoszuk U (2018) Cultural engagement and incident depression in older adults: evidence from the English Longitudinal Study of Ageing. Br J Psychiatry 214:225-229. https:// doi.org/10.1192/bjp.2018.267

17. Tymoszuk U, Perkins R, Spiro N, et al (2019) Longitudinal associations between short-term, repeated and sustained arts engagement and well-being outcomes in older adults. J Gerontol Ser B Psychol Sci Soc Sci (in press)

18. Johansson SE, Konlaan BB, Bygren LO (2001) Sustaining habits of attending cultural events and maintenance of health: a longitudinal study. Health Promot Int 16:229-234

19. Konlaan BB, Bygren LO, Johansson SE (2000) Visiting the cinema, concerts, museums or art exhibitions as determinant of survival: a Swedish fourteen-year cohort follow-up. Scand J Public Health 28:174-178

20. Cutler D (2012) Tackling loneliness in older age: the role of the arts. London: Baring Foundation and Campaign to End Loneliness. https://baringfoundation.org.uk/wp-content/uploa ds/2016/02/Loneliness.pdf. Accessed 3 Jul 2019

21. Todd C, Camic PM, Lockyer B et al (2017) Museum-based programs for socially isolated older adults: understanding what works. Health Place 48:47-55. https://doi.org/10.1016/J.HEALT HPLACE.2017.08.005

22. Hays T, Minichiello V (2005) The contribution of music to quality of life in older people: an Australian qualitative study. Ageing Soc 25:261-278. https://doi.org/10.1017/S0144686X04002946

23. Creech A, Hallam S, Varvarigou M et al (2013) Active music making: a route to enhanced subjective well-being among older people. Perspect Public Health 133:36-43. https://doi. org/10.1177/1757913912466950

24. Clements-Cortes AA (2013) Buddy's glee club: singing for life. Act Adapt Aging 37:273-290. https://doi.org/10.1080/01924 788.2013 .845716 
25. Perkins R, Williamon A (2014) Learning to make music in older adulthood: a mixed-methods exploration of impacts on wellbeing. Psychol Music 42:550-567. https://doi.org/10.1177/0305735613 483668

26. Skingley A, Martin A, Clift S, De S (2016) The contribution of community singing groups to the well-being of older people: participant perspectives from the United Kingdom. J Appl Gerontol 35:1302-1324. https://doi.org/10.1177/0733464815577141

27. Cohen GD, Perlstein S, Chapline J et al (2007) The impact of professionally conducted cultural programs on the physical health, mental health, and social functioning of older adults2-year results. J Aging, Humanit Arts 1:5-22. https://doi. org/10.1080/19325610701410791

28. Clift S, Hancox G, Morrison I et al (2010) Choral singing and psychological wellbeing: quantitative and qualitative findings from English choirs in a cross-national survey. J Appl Arts Heal 1:19-34. https://doi.org/10.1386/jaah.1.1.19/1

29. Pearce E, Launay J, Dunbar RIM (2015) The ice-breaker effect: singing mediates fast social bonding. R Soc Open Sci 2:150221. https://doi.org/10.1098/rsos.150221

30. Pearce E, Launay J, MacCarron P, Dunbar RIM (2017) Tuning into others: exploring relational and collective bonding in singing and non-singing groups over time. Psychol Music 45:496-512. https://doi.org/10.1177/0305735616667543

31. Maury S, Rickard N (2018) A comparison of the effects of shortterm singing, exercise, and discussion group activities on the emotional state and social connectedness of older Australians. Music Sci 1:205920431880060. https://doi.org/10.1177/20592 04318800607

32. Wikström B-M (2002) Social interaction associated with visual art discussions: a controlled intervention study. Aging Ment Health 6:82-87. https://doi.org/10.1080/13607860120101068

33. Gutheil IA, Heyman JC (2016) Older adults and creative arts: personal and interpersonal change. Act Adapt Aging 40:169-179. https://doi.org/10.1080/01924788.2016.1194030

34. Rose E, Lonsdale S (2016) Painting place: re-imagining landscapes for older people's subjective wellbeing. Health Place 40:58-65. https://doi.org/10.1016/j.healthplace.2016.05.002

35. FAQs How many museums are there UK?| Museums Association [Internet]. https://www.museumsassociation.org/about/frequently -asked-questions. Accessed 3 Jul 2019

36. How many theatres are there in the UK? Theatres Trust [Internet]. http://www.theatrestrust.org.uk/discover-theatres/theatrefaqs/167-how-many-theatres-are-there-in-the-uk. Accessed 3 Jul 2019

37. Number of public libraries in the UK 2002-2014| Statistic [Internet] (2015) Retrived from https://www.statista.com/statistics /290207/number-of-public-libraries-in-the-united-kingdom/. Accessed 3 Jul 2019

38. English Heritage Home Pagel English Heritage [Internet]. https:// www.english-heritage.org.uk/. Accessed 3 Jul 2019

39. Village Halls (2019) ACREl Action with Communities in Rural England [Internet]. Retrived from http://acre.org.uk/our-work/ village-halls. Accessed 3 Jul 2019

40. Steptoe A, Breeze E, Banks J, Nazroo J (2013) Cohort profile: the english longitudinal study of ageing. Int J Epidemiol 42:16401648. https://doi.org/10.1093/ije/dys 168

41. Hughes ME, Waite LJ, Hawkley LC, Cacioppo JT (2004) A short scale for measuring loneliness in large surveys: results from two population-based studies. Res Aging 26:655-672. https://doi. org/10.1177/0164027504268574

42. Steptoe A, Shankar A, Demakakos P, Wardle J (2013) Social isolation, loneliness, and all-cause mortality in older men and women. Proc Natl Acad Sci USA 110:5797-5801. https://doi.org/10.1073/ pnas. 1219686110

43. Rouxel P, Heilmann A, Demakakos P et al (2017) Oral healthrelated quality of life and loneliness among older adults. Eur J Ageing 14:101-109. https://doi.org/10.1007/s10433-016-0392-1

44. Banks J, Karlsen S, Oldfield Z (2003) Socio-economic position. In: Marmot M, Banks J, Blundell R, et al (eds) Health, Wealth and lifestyles of the older population in england. institute for fiscal studies: London pp 71-125. http://discovery.ucl.ac.uk/15366 /1/15366.pdf. Accessed 3 Jul 2019

45. Camic PM, Tischler V, Pearman CH (2014) Viewing and making art together: a multi-session art-gallery-based intervention for people with dementia and their carers. Aging Ment Health 18:161-168. https://doi.org/10.1080/13607863.2013.818101

46. Rosenberg F (2009) The MoMA Alzheimer's Project: programming and resources for making art accessible to people with Alzheimer's disease and their caregivers. Arts Health 1:93-97. https ://doi.org/10.1080/17533010802528108

47. Chatterjee H, Noble G (2013) Museums, health and well-being. Routledge, London

48. Laukka P (2007) Uses of music and psychological well-being among the elderly. J Happiness Stud 8:215-241. https://doi. org/10.1007/s10902-006-9024-3

49. Groarke JM, Hogan MJ (2018) Development and psychometric evaluation of the adaptive functions of music listening scale. Front Psychol 9:516. https://doi.org/10.3389/fpsyg.2018.00516

50. Schäfer T, Sedlmeier P, Städtler C, Huron D (2013) The psychological functions of music listening. Front Psychol 4:511. https:// doi.org/10.3389/fpsyg.2013.00511

51. Clements-Cortés A (2017) Artful wellness: attending chamber music concert reduces pain and increases mood and energy for older adults. Arts Psychother 52:41-49. https://doi.org/10.1016/J. AIP.2016.10.001

52. Fancourt D, Perkins R (2018) The effects of mother-infant singing on emotional closeness, affect, anxiety, and stress hormones. Music Sci 1:205920431774574. https://doi.org/10.1177/20592 04317745746

53. Moody E, Phinney A (2012) A community-engaged art program for older people: fostering social inclusion. Can J Aging/La Rev Can du Vieil 31:55-64. https://doi.org/10.1017/S071498081 1000596

54. Masi CM, Chen H-Y, Hawkley LC, Cacioppo JT (2011) A metaanalysis of interventions to reduce loneliness. Pers Soc Psychol Rev 15:219-266. https://doi.org/10.1177/1088868310377394

55. Taylor M (2016) Nonparticipation or different styles of participation? Alternative interpretations from Taking part. Cult trends 25:169-181. https://doi.org/10.1080/09548963.2016.1204051

56. Vanherwegen D, Lievens J (2014) The mechanisms influencing active arts participation: an analysis of the visual arts, music, and the performing arts. Sociol Inq 84:435-471. https://doi. org/10.1111/soin.12043

57. Lareau A, Weininger EB (2003) Cultural capital in educational research: a critical assessment. Theory Soc 32:567-606. https:// doi.org/10.1023/B:RYSO.0000004951.04408.b0 